\title{
Immune tolerance induction in patients with severe hemophilia A with inhibitors
}

\author{
Ji Eun Ryu ${ }^{1}$, Young Shil Park ${ }^{1}$, Ki Young Yoo ${ }^{2}$, Kyoo Duck Lee $^{3}$, Yong-Mook Choi ${ }^{2}$ \\ ${ }^{1}$ Department of Pediatrics, Kyung Hee University Hospital at Gangdong, Kyung Hee University School of Medicine, ${ }^{2}$ Korea \\ Hemophilia Foundation, ${ }^{3}$ Health Insurance Review \& Assessment Service, Seoul, Korea
}

p-ISSN 2287-979X / e-ISSN 2288-0011

http://dx.doi.org/10.5045/br.2015.50.4.248

Blood Res 2015;50:248-53.

Received on July 24, 2015

Revised on September 7, 2015

Accepted on November 4, 2015

\section{Background}

Inhibitory antibodies to factor VIII (FVIII) are an important complication when managing patients with hemophilia A. Immune tolerance induction (ITI) has been regarded as a useful method for eradicating inhibitors. We report the results of a retrospective study in Korean patients with hemophilia A who underwent ITI.

\section{Methods}

We reviewed the records of patients with hemophilia A with inhibitors who underwent ITI from March 2004 to December 2014. ITI was started with FVIII concentrates at 100 $\mathrm{IU} / \mathrm{kg}$, 3 times per week. The dose of FVIII was reduced according to the inhibitor titer and recovery of FVIII. Inhibitor elimination was defined as the time taken to achieve a negative inhibitor assay with no anamnestic response and normal FVIII recovery and/or normal half-life.

Results

In total, 17 patients with severe hemophilia A were evaluated. Complete tolerance was achieved in 14 of 17 patients (83\%). The mean peak inhibitor titer before ITI was 38.4 $\mathrm{BU} / \mathrm{mL}$. The mean treatment duration was 26.2 months. The mean duration between inhibitor detection and ITI was 5.1 years in the complete tolerance group and 10.8 years in the partial tolerance and failed group.

\section{Conclusion}

This study shows that ITI can be an effective and well-tolerated method for eradicating inhibitors. Possible influencing factors for ITI success were age at the start of ITI treatment and duration after inhibitor detection. More research to provide further insight about other factors and conditions is needed.

Key Words Hemophilia A, Inhibitor, Immune tolerance induction

\section{INTRODUCTION}

Factor VIII (FVIII) replacement therapy is an important treatment for hemophilia A. However, the development of inhibitors against FVIII is the most serious complication of replacement therapy in patients with hemophilia $\mathrm{A}[1$, 2]. Inhibitors render FVIII replacement therapy ineffective and make it difficult to control bleeding [2]. Bypassing agents, such as recombinant activated factor VII and activated prothrombin complex concentrate (APCC), are used to treat acute bleeding in patients with hemophilia A with inhibitors. However, these agents can result in increased disease-related morbidity, with high costs and inconsistent predictability of hemostatic effects [3]. The only proven strategy for achieving antigen-specific tolerance to clotting factors is immune tolerance induction (ITI) [1, 3]. ITI involves the repeated administration of FVIII concentrates over a period of weeks to years, with the goal of inducing antigen-specific tolerance [4]. Success rates for ITI vary from approximately $45 \%$ to $80 \%$ depending on the protocol. Several factors are believed to influence the outcome of ITI therapy [5].

We herein report the results of a retrospective study in patients with hemophilia A with inhibitors who underwent ITI. We investigated host- and treatment-related factors known or suspected to impact ITI outcome. 


\section{MATERIALS AND METHODS}

\section{Subjects}

A retrospective medical chart review was conducted on patients with hemophilia A with persistent inhibitors from March 2004 to December 2014 at the Korea Hemophilia Foundation Clinic. Patients with a history of severe hemophilia A and inhibitors were included in this study. The inclusion criteria were severe hemophilia A (FVIII:C $<1 \%$ ), a historical inhibitor titer of $>5 \mathrm{BU} / \mathrm{mL}$, a pre-ITI inhibitor titer of $<10 \mathrm{BU} / \mathrm{mL}$, and good compliance. The inclusion criteria were reviewed by the hemophilia committee of the Health Insurance Review and Assessment Service.

\section{ITI regimen with 3 phases}

The induction phase started with the administration of FVIII concentrates at a dosage of $100 \mathrm{IU} / \mathrm{kg} 3$ times per week for 12 to 48 weeks. The inhibitor titer and FVIII recovery were checked every 2 weeks. If the inhibitor titer was $<0.6 \mathrm{BU} / \mathrm{mL}$ or FVIII recovery was $>66 \%$ of expected for 12 weeks, the patients proceeded to the reduction phase. If the inhibitor titer decreased steadily but did not become negative, the patients received FVIII concentrates daily and the induction phase was continued for a total of 48 weeks (an additional 36 weeks). If the inhibitor titer tended to increase or plateaued after an initial anamnestic response for 10 weeks, the patients were considered to be tolerance failures and were taken off ITI.

The reduction phase took 12 weeks at a dosage of 50 $\mathrm{IU} / \mathrm{kg}$, three times per week. Inhibitor titer and FVIII recovery measurements were carried out every 4 weeks. If the inhibitor titer was $<0.6 \mathrm{BU} / \mathrm{mL}$ or FVIII recovery was $>66 \%$ of expected for 12 weeks, the patient proceeded to the maintenance phase.

The maintenance phase lasted 12 weeks. Factor VIII concentrates were given at $25 \mathrm{IU} / \mathrm{kg}$, 3 times per week. Inhibitor titer and FVIII recovery measurements were carried out every 8 weeks.

\section{Treatment for bleeding episodes during ITI}

Bleeding events were classified as major (joint and muscle) and other (gastrointestinal, urogenital, skin, and gingival bleeding) bleeding that required clotting factor concentrate supplements more than twice. The frequency of bleeding was compared in the 1 year before, during, and 1 year after ITI. During ITI, if the inhibitor titer was $\geq 5 \mathrm{BU} / \mathrm{mL}$ and bleeding occurred, bypassing agents were administered. However, once the inhibitor titer was $<5 \mathrm{BU} / \mathrm{mL}$ and FVIII recovery was $>40 \%$, patients were treated with FVIII concentrates.

Vaccinations and scheduled surgeries were avoided because these are recognized as a danger during the induction phase [6]. To reduce bleeding events, patients who had several bleeding episodes, and especially patients with chronic synovitis, were treated with maintenance therapy with APCC 3 times per week during the first 3 months. All patients were treated via a peripheral intravenous line.

\section{Definitions and evaluation of ITI}

Complete tolerance was defined as an inhibitor titer of $<0.6 \mathrm{BU} / \mathrm{mL}$ for at least 12 weeks, FVIII recovery of $>66 \%$ of expected, and a half-life of $>6$ hours after a 72-hour washout period. Partial tolerance was defined as conversion of high-responder to low-responder patients (inhibitor titer of $\leq 5 \mathrm{BU}$ ) whose bleeding episodes could be treated with FVIII concentrates. Failure was defined as an increased inhibitor titer or a plateau after an initial anamnestic response for 10 weeks.

Factors that affected ITI were the inhibitor titer, FVIII recovery, and the frequency of bleeding events. The inhibitor titer and FVIII recovery were checked every 2 and 4 weeks, respectively, for at least 3 months, except in children who had difficulties with frequent blood tests. If the inhibitor titer and FVIII recovery decreased, the inhibitor titer and FVIII recovery were checked every 1 and 3 months, respectively. After ITI therapy, these were measured at 1,3 , and 6 months and then every 6 months to check for recurrence.

\section{Statistics}

All patients who met inclusion criteria were enrolled in the study and were eligible for analysis of efficacy and safety. Patient population, efficacy, and safety data were assessed using descriptive statistics, and all analyses were exploratory. The subjects were grouped according to ITI outcome, and 2-tailed $P$ values were calculated using the Mann-Whitney test, comparing the means by t-test between the complete tolerance group, and the partial tolerance and failure group. Success of ITI according to dose, number of interruptions, presence or absence of infections, peak inhibitor titer before ITI, inhibitor titer at the start of ITI, and time between inhibitor detection and ITI start were also assessed using descriptive statistics. Bleeding frequency in the 1 year before, during, and 1 year after ITI were compared using the Friedman test.

\section{RESULTS}

\section{Patient characteristics and treatment-related data}

In total, 17 patients with hemophilia A with persistent inhibitors were evaluated. Patient demographics and clinical characteristics are shown in Table 1. The mean age at the onset of ITI was 8.8 (range, 2.8-21.6) years. The interval between inhibitor detection and ITI initiation ranged from 2.1 to 14.8 years, with a mean of 6.1 years. The mean historical peak inhibitor titer before ITI was 38.4 (range, 7.2-90.0) $\mathrm{BU} / \mathrm{mL}$. The inhibitor titer at the start of ITI ranged from 0.6 to $8.6 \mathrm{BU} / \mathrm{mL}$ with a mean of $4.0 \mathrm{BU} / \mathrm{mL}$. The mean maximum inhibitor titer during ITI was 24.7 (range, 0.6-80.0) $\mathrm{BU} / \mathrm{mL}$. The mean treatment duration of ITI was 26.2 (range, 8.5-40.7) months. $F 8$ gene mutation studies were performed. Among the mutations, intron 22 inversions accounted for the greatest proportion at 35\% (6/17). Plasma-derived FVIII/von Willebrand factor (pdFVIII/VWF) concentrates were used in 11 patients $(65 \%)$, whereas 4 patients (23\%) 
Table 1. Patient demographics and clinical characteristics.

\begin{tabular}{|c|c|c|c|c|c|c|c|c|c|c|c|c|c|}
\hline \multirow[b]{2}{*}{$\begin{array}{l}\text { Case } \\
\text { no. }\end{array}$} & \multirow[b]{2}{*}{$\begin{array}{l}\text { F8 gene } \\
\text { mutation }\end{array}$} & \multirow{2}{*}{$\begin{array}{c}\text { Age at } \\
\text { hemophilia } \\
\text { diagnosis } \\
(\mathrm{mo})\end{array}$} & \multirow{2}{*}{$\begin{array}{l}\text { Age at } \\
\text { inhibitor } \\
\text { detection } \\
(y r)\end{array}$} & \multirow{2}{*}{$\begin{array}{l}\text { CED } \\
\text { at ID } \\
\text { (d) }\end{array}$} & \multirow{2}{*}{$\begin{array}{l}\text { Age at } \\
\text { ITI (yr) }\end{array}$} & \multirow{2}{*}{$\begin{array}{l}\text { Duration } \\
\text { between } \\
\text { inhibitor } \\
\text { detection } \\
\text { and ITI (yr) }\end{array}$} & \multicolumn{3}{|c|}{ Inhibitor titer (BU/mL) } & \multirow{2}{*}{$\begin{array}{l}\text { Dose }(\mathrm{IU} / \mathrm{kg}) / \\
\text { number of } \\
\text { injections } \\
\left(\mathrm{wk}^{-1}\right)\end{array}$} & \multirow{2}{*}{$\begin{array}{l}\text { Type of } \\
\text { FVIII } \\
\text { during ITI }\end{array}$} & \multirow{2}{*}{$\begin{array}{c}\text { ITI } \\
\text { duration } \\
\text { (mo) }\end{array}$} & \multirow{2}{*}{$\begin{array}{l}\text { Out- } \\
\text { come }\end{array}$} \\
\hline & & & & & & & $\mathrm{HP}$ & $\begin{array}{l}\text { Onset } \\
\text { of ITI }\end{array}$ & $\begin{array}{c}\text { Max. } \\
\text { During ITI }\end{array}$ & & & & \\
\hline 1 & Int22inv. & 7.0 & 6.0 & UK & 11.1 & 5.1 & 26.4 & 8.6 & 32.4 & $96.8 / 3$ & $\mathrm{Pd}+\mathrm{R}$ & 40.0 & CT \\
\hline 2 & Nonsense & 1.0 & 1.0 & 14 & 4.0 & 3.0 & 22.8 & 6.2 & 36.0 & $107.3 / 7^{\mathrm{a})}$ & $\mathrm{R}$ & 38.4 & CT \\
\hline 3 & Frameshift & 8.0 & 1.0 & 77 & 3.4 & 2.4 & 10.3 & 2.0 & 0.6 & 107.1/3 & $\mathrm{R}$ & 8.5 & CT \\
\hline 4 & Frameshift & 6.0 & 3.0 & 12 & 10.0 & 7.0 & 7.2 & 0.7 & 1.1 & $24.2 / 3$ & $\mathrm{R}$ & 27.7 & CT \\
\hline 5 & Nonsense & 4.0 & 0.9 & 16 & 3.4 & 2.5 & 51.2 & 2.7 & 3.6 & $108.0 / 3$ & $\mathrm{R}$ & 13.0 & CT \\
\hline 6 & Int22inv. & 6.0 & 1.0 & 16 & 5.8 & 4.8 & 83.2 & 6.3 & 43.2 & $90.3 / 3$ & $\mathrm{Pd}$ & 12.4 & CT \\
\hline 7 & Int22inv. & 0.5 & 2.0 & 26 & 5.8 & 3.8 & 61.6 & 5.6 & 14.4 & $95.2 / 3$ & $\mathrm{Pd}$ & 23.4 & CT \\
\hline 8 & Frameshift & 6.0 & 2.0 & 56 & 5.8 & 3.8 & 41.6 & 3.8 & 80.0 & $90.9 / 7^{\mathrm{a})}$ & $\mathrm{Pd}$ & 25.6 & CT \\
\hline 9 & Frameshift & 9.0 & 0.8 & 12 & 2.8 & 2.1 & 46.4 & 3.5 & 15.2 & $76.3 / 3$ & $\mathrm{Pd}$ & 25.8 & CT \\
\hline 10 & Int22inv. & 8.0 & 1.0 & 30 & 3.1 & 2.1 & 10.4 & 1.7 & 3.08 & $87.0 / 3$ & $\mathrm{Pd}$ & 22.4 & CT \\
\hline 11 & Int22inv. & 1.0 & 2.0 & UK & 4.1 & 2.1 & 10.8 & 3.7 & 6.4 & $100.0 / 3$ & $\mathrm{Pd}$ & 18.2 & CT \\
\hline 12 & Exon del. & 0.2 & 6.0 & UK & 20.8 & 14.8 & 90.0 & 2.2 & 0.9 & $101.4 / 3$ & $\mathrm{Pd}$ & 39.1 & CT \\
\hline 13 & Nonsense & 8.0 & 11.0 & 38 & 21.6 & 10.6 & 67.2 & 0.6 & 10.4 & $98.6 / 3$ & $\mathrm{Pd}$ & 33.1 & CT \\
\hline 14 & Nonsense & 6.0 & 1.0 & 8 & 8.5 & 7.5 & 14.4 & 8.2 & 57.6 & $93.8 / 7^{\text {a) }}$ & $\mathrm{Pd}$ & 40.7 & CT \\
\hline 15 & Nonsense & 5.0 & 0.8 & UK & 8.4 & 7.7 & 52.0 & 5.2 & 6.0 & $41.7 / 7^{\mathrm{a})}$ & $P d+R$ & 19.5 & PT \\
\hline 16 & Int22inv. & 10.0 & 3.0 & 3 & 17.1 & 14.1 & 26.2 & 3.0 & 80.0 & $99.5 / 7^{\text {a) }}$ & $\mathrm{Pd}$ & 26.5 & $\mathrm{~F}$ \\
\hline 17 & Exon del. & 44.0 & 3.0 & UK & 13.7 & 10.7 & 30.8 & 4.0 & 28.8 & $93.0 / 3$ & $\mathrm{Pd}$ & 31.5 & $\mathrm{~F}$ \\
\hline $\begin{array}{c}\text { Mean } \pm \\
\text { SD }\end{array}$ & - & $\begin{array}{r}7.6 \pm \\
9.8\end{array}$ & $\begin{array}{r}2.7 \pm \\
2.7\end{array}$ & - & $\begin{array}{r}8.8 \pm \\
6.1\end{array}$ & $\begin{array}{r}6.1 \pm \\
4.2\end{array}$ & $\begin{array}{r}38.4 \pm \\
26.1\end{array}$ & $\begin{array}{r}4.0 \pm \\
2.4\end{array}$ & $\begin{array}{r}24.7 \pm \\
26.7\end{array}$ & - & - & $\begin{array}{r}26.2 \pm \\
10.0\end{array}$ & - \\
\hline
\end{tabular}

${ }^{a)}$ The number of injection increased from 3 times a week to every day.

Abbreviations: CED, cumulative exposure days to FVIII; ID, inhibitor detection; ITI, immune tolerance induction; Int22inv., intron 22 inversion; Exon del, exon deletion; UK, unknown; HP, historical peak; FVIII, factor VIII; Pd, plasma-derived FVIII/von Willebrand factor; R, recombinant; $\mathrm{CT}$, complete tolerance; PT, partial tolerance; F, failure.

received recombinant FVIII concentrates. Two patients (12\%) received more than 2 FVIII concentrates because of an unstable drug supply during ITI.

\section{ITI outcomes and effectiveness}

Among the 17 patients, complete tolerance was achieved in $14(83 \%)$, partial tolerance in $1(6 \%)$, and failure in the remaining $2(11 \%)$ patients. In the complete tolerance group, the mean inhibitor titer at completion of ITI was $0.3 \mathrm{BU} / \mathrm{mL}$ and FVIII recovery was $1.8 \% / \mathrm{IU} / \mathrm{kg}$. Complete tolerance with ITI was achieved within a mean time of 2.2 (range, 0.7-3.3) years. The time for the inhibitor to become undetectable $(<0.6 \mathrm{BU} / \mathrm{mL})$ ranged from 2 to 34 (mean, 11.9) months in the complete tolerance group.

Comparison of outcomes between the complete tolerance and partial tolerance and failure group was performed according to the clinical and treatment-related factors (Table 2). Comparison of the clinical parameters of the 2 groups revealed a significant difference in duration between inhibitor detection and ITI, with a shorter duration of 5.1 (range, $2.1-14.6)$ years in the complete tolerance group $(P=0.032)$ compared with 10.8 (range, 7.7-14.1) years in the partial tolerance and failure group. Mean age of complete tolerance group at the start of ITI was 7.9 (2.8-21.6) years old, and all patients who were $<8$ years old achieved complete tolerance. However, all patients in the partial tolerance and failure group were $>8$ years old, and their mean age at the start of ITI was 13.0 (range, 13.7-17.1) years. The inhibitor titer at ITI start and the peak inhibitor titer showed no clear relationship with outcome.

Results of $F 8$ genotyping indicated that of 6 patients with an intron 22 inversion, 5 patients (83\%) achieved complete tolerance and $1(17 \%)$ failed. ITI failed in one patient with an exon deletion and achieved partial tolerance in 1 patient with a nonsense mutation.

The number of major bleeding episodes decreased over time: 16 times before ITI, 11 times during ITI, and 4 times after ITI. Other individual bleeding events were also observed 18,7 , and 4 times before, during, and after ITI, respectively (Table 3). To identify whether bleeding events decreased after ITI according to the period of ITI, the changes between 1 year before ITI and 1 year after ITI were compared, and significant decreases were observed in both major bleeding and other bleeding events ( $P=0.027$ and 0.005 , respectively).

\section{Safety and complications}

No adverse reactions or thromboembolisms were observed during ITI. No deaths occurred during treatment. No patient discontinued ITI therapy because of an adverse event. All patients who were successfully tolerized or achieved a partial 
Table 2. Comparison of ITI outcomes between complete tolerance group and partial tolerance and failure group.

\begin{tabular}{|c|c|c|c|}
\hline & Complete tolerance $(\mathrm{N}=14)$ & Failure and partial tolerance $(\mathrm{N}=3)$ & $P^{\text {a) }}$ \\
\hline \multicolumn{4}{|c|}{ Age at hemophilia A diagnosis (mo) } \\
\hline Mean \pm SD & $5.0 \pm 3.1$ & $20.0 \pm 21.0$ & 0.127 \\
\hline \multicolumn{4}{|l|}{ Age at ID (yr) } \\
\hline Mean \pm SD & $2.7 \pm 3.0$ & $2.2 \pm 1.3$ & 0.949 \\
\hline \multicolumn{4}{|l|}{ Age at ITI (yr) } \\
\hline Mean \pm SD & $7.9 \pm 6.2$ & $13.0 \pm 4.4$ & 0.13 \\
\hline$\leq 8, \mathrm{~N}(\%)$ & $9(100)$ & $0(0)$ & - \\
\hline$>8, \mathrm{~N}(\%)$ & $5(62.5)$ & $3(37.5)$ & - \\
\hline \multicolumn{4}{|c|}{ Historical peak inhibitor titer $(\mathrm{BU} / \mathrm{mL})$} \\
\hline Mean \pm SD & $38.8 \pm 28.5$ & $36.3 \pm 13.8$ & 0.900 \\
\hline$\leq 200, \mathrm{~N}(\%)$ & $15(88.2)$ & $2(11.8)$ & - \\
\hline$>200, \mathrm{~N}(\%)$ & $0(0)$ & $0(0)$ & - \\
\hline \multicolumn{4}{|c|}{ Inhibitor titer at ITI start (BU/mL) } \\
\hline Mean \pm SD & $4.0 \pm 2.6$ & $4.0 \pm 1.1$ & 0.705 \\
\hline$\leq 10, \mathrm{~N}(\%)$ & $14(82.3)$ & $3(17.7)$ & - \\
\hline$>10, \mathrm{~N}(\%)$ & $0(0)$ & $0(0)$ & - \\
\hline \multicolumn{4}{|l|}{ Duration between ID and ITI (yr) } \\
\hline Mean \pm SD & $5.1 \pm 3.7$ & $10.8 \pm 3.2$ & 0.032 \\
\hline$\leq 5, \mathrm{~N}(\%)$ & $9(100)$ & $0(0)$ & - \\
\hline$>5, \mathrm{~N}(\%)$ & $5(62.5)$ & $3(37.5)$ & - \\
\hline \multicolumn{4}{|c|}{ Maximum inhibitor titer during ITI } \\
\hline Mean \pm SD & $21.7 \pm 24.7$ & $38.3 \pm 37.9$ & 0.413 \\
\hline \multicolumn{4}{|l|}{ F8 gene mutation } \\
\hline Intron 22 inversion, N (\%) & $5(83)$ & $1(17)$ & - \\
\hline Frameshift, $N(\%)$ & $4(100)$ & $0(0)$ & - \\
\hline Nonsense, N (\%) & $4(80)$ & $1(20)$ & - \\
\hline Deletion, $\mathrm{N}(\%)$ & $1(50)$ & $1(50)$ & - \\
\hline \multicolumn{4}{|l|}{ Type of FVIII during ITI } \\
\hline Recombinant, N (\%) & $4(100)$ & $0(0)$ & - \\
\hline pdVWF/FVIII, N (\%) & $9(82)$ & $2(18)$ & - \\
\hline mixed, $\mathrm{N}(\%)$ & $1(50)$ & $1(50)$ & - \\
\hline
\end{tabular}

${ }^{\text {a) }} P$ value by t-test between complete tolerance group and partial tolerance and failure group.

Abbreviations: ITI, immune tolerance induction; ID, inhibitor detection; FVIII, factor VIII; pdVWF, plasma-derived von Willebrand factor.

Table 3. Bleeding events occurred before, during, and after ITI.

\begin{tabular}{lcccccc} 
& \multicolumn{3}{c}{ Major bleeding events $^{\mathrm{a})}$} & \multicolumn{3}{c}{ Other bleeding events $^{\mathrm{a})}$} \\
\cline { 2 - 5 } & Before ITI $^{\mathrm{b})}$ & During ITI & After ITI $^{\mathrm{c})}$ & Before ITI $^{\mathrm{b})}$ & During ITI & After ITI $^{\mathrm{c})}$ \\
\hline $\mathrm{N}$ & 16 & 11 & 4 & 18 & 7 & 4 \\
Mean \pm SD & $17.0 \pm 6.0$ & $13.5 \pm 12.5$ & $6.7 \pm 7.6$ & $21.5 \pm 8.2$ & $8.4 \pm 7.2$ & $6.3 \pm 6.1$ \\
$P^{\mathrm{d})}$ & & 0.027 & & & 0.005 & \\
\hline
\end{tabular}

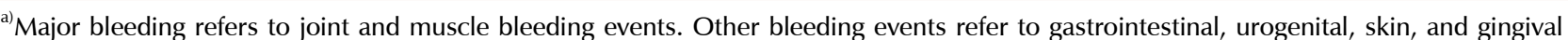
bleeding. ${ }^{\text {b) }}$ One year before ITI. ${ }^{\text {c) }}$ One year after ITI. ${ }^{\text {d) }} P$ value by $\chi^{2}$ comparing before, during, and after ITI.

Abbreviation: ITI, immune tolerance induction.

response continued on prophylactic recombinant FVIII concentrate replacement therapy.

\section{DISCUSSION}

The development of FVIII antibodies is a serious complication of hemophilia A treatment. Treatment of acute bleeding episodes becomes difficult, and the response to treatment is not always predictable in patients with hemophilia A with inhibitors [1-3]. Since ITI was first reported by Brackmann and Gormsen in 1977 [7], several other studies have developed varying doses and schedules with reasonably good success rates $(45 \%-87 \%)[5,8,9]$. In our study, complete immune tolerance was achieved in 14 of $17(83 \%)$ patients in a mean time of 2.2 years of ITI. On average, our success rate was 
higher than the success rates reported previously.

Based on studies reported to date, several factors may affect the success of ITI. These include the age at inhibitor development and age at ITI initiation, duration between inhibitor detection and ITI initiation, inhibitor titer at start of ITI, peak historical titers before and during ITI, and the dose, regimen, and type of concentrates. The International ITI Study and other previous studies defined poor risk factors as an age of $>8$ years, presence of inhibitors for $>12$ months, peak inhibitor titer of $>200 \mathrm{BU} / \mathrm{mL}$, duration between inhibitor detection and ITI of $>5$ years, and inhibitor titer at the start of ITI of $>10 \mathrm{BU} / \mathrm{mL}$ [10]. An inhibitor titer measuring $<10 \mathrm{BU} / \mathrm{mL}$ before starting ITI was the most powerful predictor of success [11-13]. Also, the higher the anamnestic peak titer, the lower the likelihood of tolerization [13]. However, considering the mean value of each item in our study, the duration between the first positive inhibitor test and ITI start in the complete tolerance group was shorter than that in the partial tolerance and failure group. The period of antibody retention in the failure group was also longer than in the successful group. Additionally, all failed patients had $>5$ years between the first positive inhibitor test and the start of ITI. All patients aged $<8$ years at ITI start achieved complete tolerance. However, all patients who failed in our study were $>8$ years old when ITI started. Thus, the age at ITI start and the duration between the first positive inhibitor test and ITI start were apparently important factors that affected the results. The influence of mutation type on ITI outcome has been investigated $[14,15]$. The success rate in our patients with intron 22 inversion was $83 \%$, higher than in those carrying other $F 8$ mutations.

Eradication of inhibitors by ITI has been attempted by several investigators using different protocols. Recent case series $[5,14]$ and in vitro studies [16] have suggested a potential additional role for FVIII concentrates with a high content of VWF in ITI $[17,18]$. The use of pdFVIII/VWF concentrates was previously shown to be effective in patients with poor prognostic factors, with success rates of $32 \%$ to $53 \%$ [14, $17,19,20]$. In our study, 11 of 17 (65\%) patients used pdFVIII/VWF concentrates, and the success rate was $82 \%$ (9/11).

One disadvantage and side effect of ITI is the need for reliable venous access, which often requires the placement of a central venous catheter [15], which can result in infection $[21,22]$. In our study, only a peripheral intravenous line was used, and no infection occurred. Another disadvantage is the cost of large amounts of FVIII concentrates during ITI. However, the number of bleeding events was effectively decreased after ITI. The bleeding events after ITI success could be treated using FVIII replacement therapy. Thus, the costs could be reduced after ITI, and the effectiveness of treatment could also be increased. This may be a good reason for continuing ITI.

It was difficult to compare with the 2 groups in our study (the complete tolerance group, and the partial tolerance and failure group) and no formal statistical comparisons were possible because the sample size (particularly for subgroup analyses) was too small. The results of our study should be interpreted with caution, and no specific recommendations on the optimal FVIII dosage or treatment duration for ITI therapy can be made. In our study, all patients had historical antibody levels of $<200 \mathrm{BU} / \mathrm{mL}$. No patient had an inhibitor titer of $>10 \mathrm{BU} / \mathrm{mL}$ at onset of ITI (mean, 4.0 BU/mL). This enabled prediction of a good result.

A standard ITI regimen does not yet exist [23, 24]. For this reason, more studies of known or suspected factors related to ITI are needed. In Korea, ITI has recently been attempted with different techniques to improve the success rate. Furthermore, studies on the use of rituximab [24], cyclophosphamide, and intravenous immunoglobulin are still in progress in patients with hemophilia A with persistent inhibitors who have poor risk factors for ITI.

In conclusion, this retrospective, non-interventional analysis performed in patients with severe hemophilia A and inhibitors showed that age at ITI start and the duration between the first positive inhibitor test and ITI start could be important factors. The most effective regimen and factors responsible for successful ITI are still being discussed.

\section{ACKNOWLEDGMENTS}

Statistical analysis was provided by Mystats, an independent consultant.

\section{Authors' Disclosures of Potential Conflicts of Interest}

No potential conflicts of interest relevant to this article were reported.

\section{REFERENCES}

1. Morfini M, Haya S, Tagariello G, et al. European study on orthopaedic status of haemophilia patients with inhibitors. Haemophilia 2007;13:606-12.

2. DiMichele DM, Hoots WK, Pipe SW, Rivard GE, Santagostino E. International workshop on immune tolerance induction: consensus recommendations. Haemophilia 2007;13(Suppl 1):1-22.

3. Matzinger P. Tolerance, danger, and the extended family. Annu Rev Immunol 1994;12:991-1045.

4. Hay CR, Baglin TP, Collins PW, Hill FG, Keeling DM. The diagnosis and management of factor VIII and IX inhibitors: a guideline from the UK Haemophilia Centre Doctors' Organization (UKHCDO). Br J Haematol 2000;111:78-90.

5. Greninger DA, Saint-Remy JM, Jacquemin M, Benhida A, DiMichele DM. The use of factor VIII/von Willebrand factor concentrate for immune tolerance induction in haemophilia A patients with high-titre inhibitors: association of clinical outcome with inhibitor epitope profile. Haemophilia 2008;14:295-302.

6. Hwang TJ. Annual report of Korea Hemophilia Foundation 2012. Seoul, Korea: Korea Hemophilia Foundation, 2012:22.

7. Brackmann HH, Gormsen J. Massive factor-VIII infusion in 
haemophiliac with factor-VIII inhibitor, high responder. Lancet 1977;2:933.

8. Auerswald G, Spranger T, Brackmann HH. The role of plasmaderived factor VIII/von Willebrand factor concentrates in the treatment of hemophilia A patients. Haematologica 2003;88: EREP05.

9. Unuvar A, Warrier I, Lusher JM. Immune tolerance induction in the treatment of paediatric haemophilia A patients with factor VIII inhibitors. Haemophilia 2000;6:150-7.

10. Hay CR, DiMichele DM; International Immune Tolerance Study. The principal results of the International Immune Tolerance Study: a randomized dose comparison. Blood 2012;119:1335-44.

11. Valentino LA, Kempton CL, Kruse-Jarres R, et al. US Guidelines for immune tolerance induction in patients with haemophilia a and inhibitors. Haemophilia 2015;21:559-67.

12. Mariani G, Ghirardini A, Bellocco R. Immune tolerance in hemophilia-principal results from the International Registry. Report of the factor VIII and IX Subcommittee. Thromb Haemost 1994;72:155-8.

13. DiMichele DM, Kroner BL; North American Immune Tolerance Study Group. The North American Immune Tolerance Registry: practices, outcomes, outcome predictors. Thromb Haemost 2002;87:52-7.

14. Orsini F, Rotschild C, Beurrier P, Faradji A, Goudemand J, Polack B. Immune tolerance induction with highly purified plasmaderived factor VIII containing von Willebrand factor in hemophilia A patients with high-responding inhibitors. Haematologica 2005;90:1288-90.

15. Kurth M, Puetz J, Kouides $P$, et al. The use of a single von Willebrand factor-containing, plasma-derived FVIII product in hemophilia A immune tolerance induction: the US experience. J Thromb Haemost 2011;9:2229-34.
16. Kurth MA, Dimichele D, Sexauer C, et al. Immune tolerance therapy utilizing factor VIII/von Willebrand factor concentrate in haemophilia A patients with high titre factor VIII inhibitors. Haemophilia 2008;14:50-5.

17. Gringeri A, Musso R, Mazzucconi MG, et al. Immune tolerance induction with a high purity von Willebrand factor/VIII complex concentrate in haemophilia A patients with inhibitors at high risk of a poor response. Haemophilia 2007;13:373-9.

18. Sukhu K, Keeling DM, Giangrande PL. Variation in inhibitor reactivity in acquired haemophilia A with different concentrates. Clin Lab Haematol 2000;22:287-90.

19. Gilles JG, Jacquemin MG, Saint-Remy JM. Factor VIII inhibitors. Thromb Haemost 1997;78:641-6.

20. Gensana M, Altisent C, Aznar JA, et al. Influence of von Willebrand factor on the reactivity of human factor VIII inhibitors with factor VIII. Haemophilia 2001;7:369-74.

21. Astermark J, Voorberg J, Lenk H, et al. Impact of inhibitor epitope profile on the neutralizing effect against plasma-derived and recombinant factor VIII concentrates in vitro. Haemophilia 2003;9:567-72.

22. Saenko EL, Ananyeva NM, Kouiavskaia DV, et al. Haemophilia A: effects of inhibitory antibodies on factor VIII functional interactions and approaches to prevent their action. Haemophilia 2002;8:1-11

23. Gringeri A, Musso R, Bernasconi S, et al. Immunotolerance induction (ITI) with high purity FVIII/VWF concentrates in inhibitors patients with a high risk of a poor response to ITI: A prospective surveillance. J Thromb Haemost (ISTH Congresses Abstracts) 2005;3(Suppl):abst 207.

24. Kim CY, Lee KN, Park YS. The use of rituximab with immune tolerance induction therapy for hemophilia A with inhibitors. Clin Pediatr Hematol Oncol 2015;22:67-71. 